\title{
Motivational Interviewing to Improve Self-efficacy in Type 2 Diabetes Management
}

\author{
Masumeh Hemmati Maslakpak \\ Urmia University of Medical Sciences School of Nursing and Midwifery \\ Naser Parizad ( $\nabla$ nparizad@gmail.com ) \\ Urmia University of Medical Sciences https://orcid.org/0000-0001-7393-3010 \\ Amir Ghahremani \\ Urmia University of Medical Sciences School of Nursing and Midwifery \\ Vahid Alinejad \\ Urmia University of Medical Sciences School of Medicine
}

\section{Research article}

Keywords: Motivational Interviewing, Self Efficacy, Type 2 Diabetes, Disease Management

Posted Date: May 20th, 2020

DOl: https://doi.org/10.21203/rs.3.rs-22939/v2

License: (9) This work is licensed under a Creative Commons Attribution 4.0 International License. Read Full License 


\section{Abstract}

Background: Self-efficacy predicts adherence to treatment in patients with diabetes. Motivational interviewing could be a promising intervention to increase the patients' motivation to follow therapeutic recommendations. The present study aimed to assess the effects of motivational interviewing on selfefficacy in type 2 diabetes management.

Methods: This quasi-experimental study with a pretest-posttest design was conducted on 60 patients with type 2 diabetes, who were members of the Bukan Diabetes Association in Iran. The patients were selected using a random number table and were randomly allocated into intervention $(n=30)$ and control $(n=30)$ groups. Five motivational interviewing sessions (30-45 minutes) were held for the intervention group (two sessions per week). Data were collected using a demographic questionnaire and the diabetes management self-efficacy scale (DMSES). Data were analyzed with SPSS software version 14.0 using descriptive and inferential statistics.

Results: Sixty patients entered the analysis. A significant difference was observed in the mean score of diabetes management self-efficacy between the two groups before and after the intervention ( $P=0.014)$. The mean score of self-efficacy in diabetes management was increased significantly in the intervention group after MI $(\mathrm{P}=0.001)$.

Conclusions: Motivational interviewing improved self-efficacy in diabetes management. Thus, this approach is recommended to be used in patients with type 2 diabetes in order to increase their selfefficacy.

\section{Background}

Diabetes is one of the major causes of mortality across the world and is associated with complications that impose a huge burden on families, communities, and governments [1]. The prevalence of diabetes has been on the rise in developed and developing countries, and this issue has been reported to be more serious in the Middle East [2]. The world prevalence of diabetes was $6.4 \%$, affecting 285 million adults in 2010 and will rise to $7.7 \%$ with 439 million adults by 2030 . In Iran, 2,872,000 cases were diagnosed with diabetes in 2010 which is expected to rise to $5,981,000$ cases by 2030 [3].

Diabetes decreases patient's quality of life and disrupts their routine activities due to sickness, absenteeism, disability, loss of productivity, early retirement or even premature death. [4]. Disease management improves the quality of care and productivity of patients with chronic diseases [5]. Disease management could be defined as a comprehensive strategy to enhance the general health status and reduce the treatment costs [6]. A disease management program had significant positive clinical impacts on the levels of hemoglobin A1C in patients with diabetes [7]. Diabetes management requires proper commitment to health behaviors. Behavioral changes seem crucial in patients with diabetes, and special attention must be paid to the effective factors in empowering these patients. Self-efficacy is one of the most important factors which play a key role in the proper management of diabetes [8]. In patients with 
diabetes, self-efficacy could predict adherence to blood glucose monitoring, diet, insulin injection, and physical exercise; therefore, higher self-efficacy was associated with better diabetes management in these patients [9]. Meybodi et al reported a significant correlation between self-efficacy and self-care behaviors of patients with diabetes and concluded that self-efficacy plays a pivotal role in successful diabetes management in these patients [10].

Motivational interviewing $(\mathrm{MI})$ is a counseling approach used by healthcare providers to help patients adhere to treatment recommendations [11]. The main purpose of motivational interviewing is to reduce the patients' perception of their own disability in order to change successfully and eliminate barriers [12]. $\mathrm{Ml}$ increases internal motivation of patients and helps them explore and resolve ambivalence [9]. In addition to increasing motivation, $\mathrm{MI}$ attracts the patients' attention to a specific topic, thereby allowing substantial changes in various behavioral patterns [13]. This counseling approach has been developed by Miller and Rollnick as a promising intervention to bring about positive health behavior in medicine, health, and psychiatry [9]. MI could be implemented individually and in groups owing to its flexibility and ability to be applied in different behavioral aspects [14]. MI approach of Miller and Rollnick aims to enhance self-efficacy and increase motivation in individuals through interactive and empathetic listening in order to change their behavior patterns [15]. Another study conducted by Chien et al showed that Ml program significantly improved self-management, self-efficacy, and quality of life in patients with schizophrenia [16]. Moreover, the literature review revealed the superiority of the MI program over traditional intervention strategies in addressing a wide range of psychological and physical disorders [10-12]. Despite the rapid growth in the application of $\mathrm{MI}$ in different areas of health care worldwide, it is a novel approach and limited research was conducted about its effectiveness in Iran. Because of the prevalence of diabetes as a chronic, disabling, and lifestyle disease that is growing so rapidly, the present study was conducted to investigate the effect of $\mathrm{MI}$ on self-efficacy in type 2 diabetes management. Our hypothesis was that $\mathrm{MI}$ might have an impact on self-efficacy in type 2 diabetes management.

\section{Methods}

\section{Study design and participants}

This quasi-experimental study with pre-test and post-test design was conducted in 2017. Participants were selected among patients with type 2 diabetes who were members of Bukan Diabetes Association in a city in west Azerbaijan located in the northwest of Iran. In total, 60 patients were selected using a random number table. The participants were allocated into the control $(n=30)$ and intervention $(n=30)$ groups by drawing " $\mathrm{A}$ " and " $\mathrm{B}$ " cards. The sample size was determined based on the study by Navidian et al with $95 \%$ confidence interval and $80 \%$ test power using the GPower 3.1 [17]. The inclusion criteria were as follows: 1) willingness to participate in the study; 2) no history of psychiatric diseases based on medical record; 3) no participation in similar MI programs; 4) no communication problems (e.g., blindness/deafness) and 5) no history of cognitive disorders. Unwillingness to participate in the study and hospitalization was considered as the exclusion criteria. 


\section{Measures}

Data were collected using a demographic questionnaire including the age, gender, occupational status, education level, marital status, duration of diabetes, and type of medications. Moreover, the diabetes management self-efficacy scale (DMSES) was applied to evaluate self-efficacy in diabetes management. DMSES is theoretically based on Bandura's self-efficacy construct and it was developed by Naderimagham et al in 2013 [18]. This instrument consists of 17 items covering five domains: a specific diet, physical exercise, blood glucose monitoring, foot care, and smoking habits. The items in DMSES are scored based on a five-point Likert scale (Completely Disagree-Completely Agree) within the score range of 17-85. In the present study, we calculated the mean score in this questionnaire. The qualitative content and construct validity of DMSES was confirmed by Noroozi et al and the internal consistency of the instrument was also confirmed by Cronbach's alpha coefficients $(a=0.92)$ [19].

\section{Intervention}

We obtained permission from the Ethics Committee of Urmia University of Medical Sciences in Iran (IR.UMSU.RCC.1395.132). We explained the purpose of the research to the participants, and assured their privacy and the confidentiality of their personal information. In addition, the participants signed an informed consent form, and they were notified of the voluntary nature of enrollment in the study. After all patients completed the questionnaire, we randomly allocated the patients to the intervention and control groups. Then, the intervention group was divided into three subgroups of 10 . The lead researcher performed Ml sessions based on the research contents showed on table 1. He had previous experience regarding $\mathrm{Ml}$ and attended in a training class in this regard. The research content was about the specific diet, physical exercise, blood glucose monitoring, foot care, and smoking habits (Table 1). The structure of the MI sessions was based on Miller and Rollnick (2012) book [9], and the intervention was implemented in five sessions (two sessions of 30-45 minutes per week). The lead researcher who was trained about the $\mathrm{Ml}$ approach, presented in each session to guide the group. The lead researcher began the session with the evaluation of the participants. Then, he set the primary goals according to the participants' evaluation results and determined the action plan. The most important skills were used in the sessions were goal setting and menu building. He provided a menu of helpful options for what is discussed and what goals are identified. The researcher then started the interview session with the group. During the interview, he led the session using the content he has already prepared. He taught and consulted the patients by using reflexive listening. He used all five principles of Motivational Interviewing during MI sessions. 1. Expressing empathy: He showed empathy to participants through reflective listening (informing patients of their abilities and acceptance, positive attention, inner purity). 2. Developing discrepancy: He tried to enhance motivation for change in the participants by developing discrepancies between their current situation and their hopes for the future. He helped them focus their attention on how current behavior differs from desired behavior (demonstrating the risks and severity of the effects of the disease that are not acknowledged by patients). 3. Avoiding arguments: He never used argument and confrontation (not trying to convince patients that an issue still exists or that change is needed). 4. Adjusting to client resistance: He tried to walk with participants and adjust to participants' 
resistance rather than confronting it directly (reflective listening to the failures of patients). 4. Support self-Efficacy: He assists participants to believe that they can start behavior changes. He helped participants to improve their self-efficacy to gain hope, optimism, and the feasibility of accomplishing change (evaluating the past successes of patients and highlighting their abilities/achievements).

\begin{tabular}{|ll|}
\hline Sessions & Structure and Contents of MI Sessions \\
\hline Orientation & Introduction, group norms and processes, and presentation of a motivational approach \\
\hline Emotions & $\begin{array}{l}\text { Emotional recognition exercises, exercise and completion of impact dimensions with } \\
\text { emotional dimension and homework assignments }\end{array}$ \\
\hline $\begin{array}{l}\text { Positive and Negative } \\
\text { Behavioral Aspects }\end{array}$ & $\begin{array}{l}\text { Brain storming exercise, short-term and long-term benefits and losses, and description } \\
\text { and practice of corrective and alternative options }\end{array}$ \\
\hline $\begin{array}{l}\text { Values } \\
\text { Defining values, performing practices to identify and prioritize first-class values, } \\
\text { practicing the definition of values, and practicing value-behavior matching }\end{array}$ \\
\hline $\begin{array}{l}\text { Vision and Final } \\
\text { Assessment }\end{array}$ & $\begin{array}{l}\text { Summary and previous session practices in the form of practicing the vision, and } \\
\text { preparation to initiate the behavioral change program }\end{array}$ \\
\hline
\end{tabular}

Table 1

Contents of MI sessions

The contents of the MI sessions were easy to understand and were provided based on the participants' education level, so that they could comprehend the teachings. The researcher initiated the first MI session by introducing himself and trying to create a friendly atmosphere. He was not allowed any prejudice, views, and knowledge affecting his behaviors in the classes, while he remained focused throughout the sessions. MI consists of four principles, including empathy (informing patients of their abilities and acceptance, positive attention, inner purity), creating conflict (demonstrating the risks and severity of the effects of the disease that are not acknowledged by patients), tolerance with resistance (reflective listening to the failures of patients), and supporting self-efficacy (evaluating the past successes of patients and highlighting their abilities/achievements). Four weeks after the intervention finished, all the patients completed the questionnaires again, and the MI sessions were implemented in the control group as well.

\section{Data analysis}

Analysis was performed on 60 patients who completed the baseline and 4-weeks follow-up assessments (Figure 1). Shapiro-Wilk test was used to determine the normal distribution of the data. Data analysis was performed using SPSS software version 14 (SPSS, Inc., Chicago, IL, USA). The descriptive (mean, standard deviation, number and percentage) and inferential (independent t-test, paired t-test, MannWhitney $U$ test, and Chi-square) statistics were used to analyze data. P-value of less than 0.05 was considered significant. 


\section{Results}

There was no significant difference between the intervention and control groups in terms of demographic characteristics $(P>0.05)$. As such, it could be claimed that the research groups were homogeneous in regards to the demographic characteristics (Table 2). 


\begin{tabular}{|c|c|c|c|c|}
\hline \multirow[t]{2}{*}{ Variable } & & Control & Intervention & \multirow[t]{2}{*}{ Chi-square test } \\
\hline & & N (\%) & N (\%) & \\
\hline \multirow[t]{2}{*}{ Gender } & Female & $14(46.66)$ & $15(50)$ & \multirow{2}{*}{$\begin{array}{l}x^{2}=0.067 \\
d f=1 \\
P=0.796\end{array}$} \\
\hline & Male & $16(53.33)$ & $15(50)$ & \\
\hline \multirow[t]{2}{*}{ History of diabetes } & Yes & $12(40)$ & $14(46.7)$ & \multirow{2}{*}{$\begin{array}{l}x^{2}=0.271 \\
d f=1 \\
P=0.602\end{array}$} \\
\hline & No & $18(60)$ & $16(53.3)$ & \\
\hline \multirow[t]{3}{*}{ Marital status } & Married & $28(93.4)$ & $28(93.4)$ & \multirow{3}{*}{$\begin{array}{l}x^{2}=0.484 \\
d f=1 \\
P=0.999\end{array}$} \\
\hline & Single & $1(3.3)$ & $1(3.3)$ & \\
\hline & Widowed & $1(3.30$ & $1(3.3)$ & \\
\hline \multirow[t]{3}{*}{ Types of medication } & Insulin & $1(3.3)$ & $3(10)$ & \multirow{3}{*}{$\begin{array}{l}X^{2}=1.643 \\
d f=2 \\
P=0.440\end{array}$} \\
\hline & Pill & $21(70)$ & $17(56.7)$ & \\
\hline & Both & $6(26.7)$ & $10(33.3)$ & \\
\hline \multirow[t]{4}{*}{ Types of occupation } & Housewife & $17(56.6)$ & $15(50)$ & \multirow{4}{*}{$\begin{array}{l}x^{2}=1.037 \\
d f=4 \\
P=0.792\end{array}$} \\
\hline & Employed & $11(36.7)$ & $10(33.33)$ & \\
\hline & Disabled & $2(6.7)$ & $3(10)$ & \\
\hline & Retired & $0(0)$ & $2(6.7)$ & \\
\hline \multirow[t]{3}{*}{ Level of education } & Primary & $19(63.3)$ & $19(63.3)$ & \multirow{3}{*}{$\begin{array}{l}x^{2}=2.933 \\
d f=2 \\
P=0.231\end{array}$} \\
\hline & Secondary & $4(13.3)$ & $8(26.7)$ & \\
\hline & Higher & $7(23.3)$ & $3(10)$ & \\
\hline Variable & & Mean \pm SD & Mean \pm SD & Independent t-test \\
\hline Age(Years) & & $55.14 \pm 7.89$ & $51.9 \pm 6.27$ & $\begin{array}{l}t=1.399 \\
d f=58 \\
P=0.162\end{array}$ \\
\hline $\begin{array}{l}\text { Duration of diabetes } \\
\text { )Years) }\end{array}$ & & $5.5 \pm 5.88$ & $7.6+6.20$ & $\begin{array}{l}t=0.897 \\
d f=58 \\
P=0.373\end{array}$ \\
\hline BMI & & $29.8 \pm 5.14$ & $30.77 \pm 4.06$ & $\begin{array}{l}t=0.766 \\
d f=58 \\
P=0.447\end{array}$ \\
\hline
\end{tabular}

Table 2

Comparison of Intervention and Control Groups in Terms of Demographic Characteristics 
There was a significant difference between the intervention and control groups regarding the mean nutrition score before and after the intervention $(P=0.006)$. In addition, the results indicated a significant difference between two groups in terms of the mean score of physical exercise before and after the intervention $(P=0.004)$. After the Ml sessions, a significant difference was observed between the two groups in terms of the self-assessment score $(P=0.0001)$. The independent $t$-test showed a significant difference regarding the mean score of foot care between two groups after the intervention $(P=0.0001)$. In contrast, no significant difference was observed in the mean score of smoking habits between the groups after the $\mathrm{Ml}$ sessions $(P=0.091)$. Moreover, independent $t$-test demonstrated a significant difference in the mean score of diabetes management self-efficacy between the two groups after the intervention $(P=0.014)$ (Table 3). 


\begin{tabular}{|c|c|c|c|c|}
\hline \multirow[t]{2}{*}{ Domains } & \multirow[t]{2}{*}{ Time } & $\begin{array}{l}\text { Control } \\
\text { group }\end{array}$ & $\begin{array}{l}\text { Intervention } \\
\text { group }\end{array}$ & \multirow[t]{2}{*}{$\begin{array}{l}\text { Independent } \mathrm{t} \text { - } \\
\text { test }\end{array}$} \\
\hline & & Mean \pm SD & Mean \pm SD & \\
\hline \multirow[t]{3}{*}{ Diet } & Before the intervention & $7.36 \pm 3.87$ & $9.43 \pm 4.16$ & $\begin{array}{l}t=2.262 \\
d f=58 \\
P=0.027\end{array}$ \\
\hline & After the intervention & $7.68 \pm 4.03$ & $13.23 \pm 4.16$ & $\begin{array}{l}t=7.06 \\
d f=58 \\
P=0.0001\end{array}$ \\
\hline & $\begin{array}{l}\text { Before and after } \\
\text { difference }\end{array}$ & $0.32 \pm 0.16$ & $3.8 \pm 1.69$ & $\begin{array}{l}t=4.08 \\
d f=58 \\
P=0.006\end{array}$ \\
\hline \multirow[t]{3}{*}{ Physical exercise } & Before the intervention & $7.11 \pm 3.95$ & $10.26 \pm 4.53$ & $\begin{array}{l}t=2.874 \\
d f=58 \\
P-0.006\end{array}$ \\
\hline & After the intervention & $7.81 \pm 4.52$ & $16.23 \pm 2.97$ & $\begin{array}{l}t=8.509 \\
d f=58 \\
P=0.0001\end{array}$ \\
\hline & $\begin{array}{l}\text { Before and after } \\
\text { difference }\end{array}$ & $0.7 \pm 0.57$ & $5.97 \pm 1.46$ & $\begin{array}{l}t=5.635 \\
d f=58 \\
P=0.004\end{array}$ \\
\hline \multirow[t]{3}{*}{ Blood glucose self-monitoring } & Before the intervention & $6.62 \pm 2.88$ & $8.7 \pm 3.03$ & $\begin{array}{l}t=7.812 \\
d f=58 \\
P=0.229\end{array}$ \\
\hline & After the intervention & $6.61 \pm 2.93$ & $12.23 \pm 2.16$ & $\begin{array}{l}t=8.447 \\
d f=58 \\
P=0.0001\end{array}$ \\
\hline & $\begin{array}{l}\text { Before and after } \\
\text { difference }\end{array}$ & $0.01 \pm 0.08$ & $3.53 \pm 0.87$ & $\begin{array}{l}t=0.635 \\
d f=58 \\
P=0.0001\end{array}$ \\
\hline \multirow[t]{3}{*}{ Foot care } & Before the intervention & $\begin{array}{l}10.04 \pm \\
5.18\end{array}$ & $10.55 \pm 4.74$ & $\begin{array}{l}t=0.121 \\
d f=58 \\
P=0.904\end{array}$ \\
\hline & After the intervention & $\begin{array}{l}10.17 \pm \\
5.30\end{array}$ & $18.13 \pm 2.25$ & $\begin{array}{l}t=0.755 \\
d f=58 \\
P=0.0001\end{array}$ \\
\hline & $\begin{array}{l}\text { Before and after } \\
\text { difference }\end{array}$ & $0.13 \pm 0.12$ & $7.58 \pm 2.49$ & $\begin{array}{l}\mathrm{t}=0.634 \\
\mathrm{df}=58 \\
\mathrm{P}=0.0001\end{array}$ \\
\hline \multirow[t]{2}{*}{ Smoking } & Before the intervention & $\begin{array}{l}12.66 \pm \\
3.44\end{array}$ & $13.70 \pm 3.15$ & $\begin{array}{l}t=1.054 \\
d f=58 \\
P=0.296\end{array}$ \\
\hline & After the intervention & $\begin{array}{l}12.61 \pm \\
4.23\end{array}$ & $14.2 \pm 2.61$ & $\begin{array}{l}t=1.720 \\
d f=58\end{array}$ \\
\hline
\end{tabular}




\begin{tabular}{|c|c|c|c|c|}
\hline & & & & $\mathrm{P}=0.091$ \\
\hline & $\begin{array}{l}\text { Before and after } \\
\text { difference }\end{array}$ & $0.05 \pm 1.62$ & $10.5 \pm 0.54$ & $\begin{array}{l}t=0.666 \\
d f=58 \\
P=0.0001\end{array}$ \\
\hline \multirow[t]{3}{*}{$\begin{array}{l}\text { Diabetes management self- } \\
\text { efficacy }\end{array}$} & Before the intervention & $\begin{array}{l}45.09 \pm \\
13.58\end{array}$ & $53.77 \pm 13.55$ & $\begin{array}{l}\mathrm{t}=2.476 \\
\mathrm{df}=58 \\
\mathrm{P}=0.016\end{array}$ \\
\hline & After the intervention & $\begin{array}{l}45.86 \pm \\
14.00\end{array}$ & $74.16 \pm 8.09$ & $\begin{array}{l}t=9.608 \\
d f=58 \\
P=0.0001\end{array}$ \\
\hline & $\begin{array}{l}\text { Before and after } \\
\text { difference }\end{array}$ & $0.77 \pm 42$ & $-20.39 \pm 5.46$ & $\begin{array}{l}t=7.132 \\
d f=58 \\
P=0.014\end{array}$ \\
\hline
\end{tabular}

Table 3

Comparison of the mean score of self-efficacy in diabetes management and its domains before and after the motivational interviewing between the intervention and control groups

There was a significant difference in the mean score of nutrition, physical exercise, self-assessment, and foot care before and after the intervention in the intervention group $(P=0.0001)$. However, no significant difference was observed in the intervention group in terms of the mean score of smoking habits before and after the intervention $(P=0.433)$. The results of paired $t$-test also demonstrated no significant difference in the mean score of diabetes management self-efficacy in the control group before and after the intervention $(P=0.744)$. Nevertheless, a significant difference was observed in the intervention group regarding the mean score of diabetes management self-efficacy before and after the intervention $(P=0.001)$ (Table 4). 


\begin{tabular}{|c|c|c|c|c|}
\hline \multirow[t]{2}{*}{ Domains } & \multirow[t]{2}{*}{ Time } & $\begin{array}{c}\text { Before the } \\
\text { intervention }\end{array}$ & $\begin{array}{c}\text { After the } \\
\text { intervention }\end{array}$ & \multirow[t]{2}{*}{$\begin{array}{l}\text { Independent t- } \\
\text { test }\end{array}$} \\
\hline & & Mean \pm SD & Mean \pm SD & \\
\hline \multirow[t]{2}{*}{ Diet } & Control group & $7.36 \pm 3.87$ & $7.68 \pm 4.03$ & $\begin{array}{c}t=0.413 \\
d f=29 \\
P=0.683\end{array}$ \\
\hline & $\begin{array}{l}\text { Intervention } \\
\text { group }\end{array}$ & $9.43 \pm 3.16$ & $13.23 \pm 1.47$ & $\begin{array}{c}t=8.627 \\
d f=29 \\
P=0.0001\end{array}$ \\
\hline \multirow[t]{2}{*}{ Physical exercise } & Control group & $7.11 \pm 3.95$ & $7.81 \pm 4.52$ & $\begin{array}{c}t=0.918 \\
d f=29 \\
P=0.366\end{array}$ \\
\hline & $\begin{array}{l}\text { Intervention } \\
\text { group }\end{array}$ & $10.26 \pm 4.53$ & $16.23 \pm 2.97$ & $\begin{array}{c}t=10.425 \\
d f=29 \\
p=0.0001\end{array}$ \\
\hline \multirow[t]{2}{*}{ Blood glucose self-monitoring } & Control group & $6.62 \pm 2.88$ & $6.61 \pm 2.93$ & $\begin{array}{c}t=-0.037 \\
d f=58 \\
p=0.970\end{array}$ \\
\hline & $\begin{array}{l}\text { Intervention } \\
\text { group }\end{array}$ & $8.7 \pm 3.03$ & $12.23 \pm 2.16$ & $\begin{array}{c}t=8.006 \\
d f=58 \\
p=0.0001\end{array}$ \\
\hline \multirow[t]{2}{*}{ Foot care } & Control group & $10.04 \pm 5.18$ & $10.17 \pm 5.30$ & $\begin{array}{c}t=-0.257 \\
d f=29 \\
p=0.799\end{array}$ \\
\hline & $\begin{array}{l}\text { Intervention } \\
\text { group }\end{array}$ & $10.55 \pm 4.74$ & $18.13 \pm 2.25$ & $\begin{array}{c}\mathrm{t}=10.371 \\
\mathrm{df}=29 \\
\mathrm{p}=0.0001\end{array}$ \\
\hline \multirow[t]{2}{*}{ Smoking } & Control group & $12.66 \pm 3.44$ & $12.61 \pm 4.33$ & $\begin{array}{c}t=-0.070 \\
d f=29 \\
p=0.945\end{array}$ \\
\hline & $\begin{array}{l}\text { Intervention } \\
\text { group }\end{array}$ & $13.70 \pm 3.15$ & $14.2 \pm 2.61$ & $\begin{array}{c}t=0.796 \\
d f=29 \\
p=0.433\end{array}$ \\
\hline \multirow[t]{2}{*}{$\begin{array}{l}\text { Diabetes management self- } \\
\text { efficacy }\end{array}$} & Control group & $45.09 \pm 13.58$ & $45.86 \pm 8.09$ & $\begin{array}{c}\mathrm{t}=12.745 \\
\mathrm{df}=29 \\
\mathrm{p}=0.744\end{array}$ \\
\hline & $\begin{array}{l}\text { Intervention } \\
\text { group }\end{array}$ & $53.77 \pm 13.55$ & $74.16 \pm 8.09$ & $\begin{array}{c}\mathrm{t}=0.413 \\
\mathrm{df}=29 \\
\mathrm{p}=0.0001\end{array}$ \\
\hline
\end{tabular}

Table 4

Comparison of the mean score of self-efficacy in diabetes management and its domains before and after the motivational interviewing within the intervention and control groups

Patients' blood glucose was improved significantly in the intervention group after the MI sessions. The mean score of blood glucose was measured and a significant difference was observed between the intervention (169 \pm 63.6$)$ and control $(210.6 \pm 96.04)$ groups before and after the intervention $(P=0.046)$. 
The results of this study indicated no significant differences in demographic characteristics between the two groups. In other words, the study groups were homogenous in terms of demographic characteristics, and any significant difference in the dependent variable was attributed to the MI sessions at the end of the study.

Our findings also demonstrated that the $\mathrm{Ml}$ approach positively influenced the nutritional self-efficacy in patients with diabetes. In addition, the MI method could effectively enhance the sense of self-efficacy in the face of negative emotions, social pressure, and physical discomfort situations, leading the patients toward performing positive and enjoyable activities. In fact, the MI approach could create sustainable and relatively long-lasting changes in all of the previously mentioned parameters. These findings confirmed the hypothesis that $\mathrm{Ml}$ is a more effective method than routine education approach in increasing the sense of self-efficacy of eating behavior as a predictor of success in weight loss programs. Baer believes that low self-confidence in the control of eating behavior, especially when experiencing negative emotions, is associated with symptoms of eating disorders [20]. Our results showed that physical exercise self-efficacy could improve in patients with diabetes after MI sessions. It might be due to enhancing optimism and positive emotions and reinforcing the self-care and self-management motivation of these patients after Ml sessions. Nowadays, experts consider physical exercise along with diet and medication as the third major pillar of diabetes treatment [21].

Our results showed the $\mathrm{Ml}$ approach positively influenced the self-monitoring of blood glucose (SMBG) in the patients with diabetes. The basic principles of $\mathrm{Ml}$ are to reinforce the sense of self-efficacy to the clients regarding all behavioral changes. Most of the Ml techniques used in this research were exclusively related to this matter, such as the evaluation of commitment-confidence, controlling temper in stimulating situations, participation in decision-making, supporting the autonomy of the clients, elimination of bias, and drawing attention to discuss change. In this respect, Simpson et al argued that the Ml approach mostly emphasizes on the support of self-efficacy, participation, and inquiries for the viewpoints of the clients [22]. Thus, creating a strong sense of self-efficacy against temptations can lead to SMBG.

Our results indicated that the MI method positively influenced foot care in the patients with diabetes. By compensating for disabilities and regulating individual performance, the $\mathrm{Ml}$ approach could improve practical care in patients. Nevertheless, the MI method had no effects on the smoking habits of the patients in the current research. Most diabetic patients have a dual sense of decision-making when it comes to change rather than resistance/poor will power. Diabetes control requires the understanding of the information and required treatment procedures, and inadequate knowledge regarding the disease control process may decrease the patients' self-confidence in this process.

After Ml sessions in our study, the mean score of diabetes management self-efficacy increased in the intervention groups. Thus, it confirmed that the implementation of the $\mathrm{Ml}$ approach could positively influence the management self-efficacy of these patients. MI has a positive impact on the self-efficacy of individuals by affecting the perceptions and increasing the mental involvement of patients to realize their conditions and learn to manage their problems independently. In this regard, our findings are in

Page 12/18 
congruence with the study by Walpole et al which was conducted to evaluate the effects of MI on increased self-efficacy in adolescents [23]. Our finding is confirmed by following studies. Song et al showed that MI had a positive impact on the self-management of patients with diabetes [24]. BóvedaFontán et al confirmed the effectiveness of MI in the management of patients with dyslipidemia [25]. In addition, Mojahed et al indicated that Ml enhanced the self-efficacy of pregnant women and helped them to quit hookah smoking [26]. In another study focusing on self-efficacy and chronic diseases, Ebrahimi Belil et al observed that increasing self-efficacy in patients resulted in creating a sense of empowerment to perform personal tasks, reducing fear, enhancing stress management, improving social relationships and promoting self-management [27]. According to Sheeran et al self-efficacy could directly affect healthrelated behaviors, as well as other cognitive determinants. Furthermore, it could be argued that individuals with higher self-efficacy have more prominent personal goals, expect better outcomes, and consider the obstacles against self-management as challenges to be overcome, all of which ultimately increase their self-management [28].

Similar to our findings, Chen et al reported an improvement in the self-efficacy of more than half of the participants in the intervention group after implementing the Ml approach [15]. In other research, MI was provided in the form of video calls as diabetes self-management education, and the results showed a significant improvement in the patients' self-efficacy [29]. Inconsistent with our results, the findings of similar research showed that educational interventions for diabetes self-management improved the glycated hemoglobin levels more significantly compared to the diabetes self-management education based on the MI approach [30]. In addition, another study demonstrated that MI had no considerable impact on the routine care of patients with types I and II diabetes [31]. The resaon could be due to high attrision rates in their studies.

\section{Study Limitations}

One of the limitations of our study was the small sample size, which might have an impact on the effect size of the study. Conducting the study in a small region, which had a specific cultural background was another limitation of the study. The cultural tendencies of individuals affect their learning abilities and implementation of the teachings. Therefore, it is suggested that further investigations be conducted in this regard with larger sample sizes and in larger areas with various cultures, so that the effects of MI on diabetes management self-efficacy could be confirmed, and the results could be generalized with greater confidence.

\section{Conclusions}

Self-efficacy plays a key role in the prediction of self-care activities in patients' with diabetes, and diabetes management self-efficacy could be improved through implementing the MI approach and increasing the motivation of the patients. Our findings could be used in various fields, such as nursing management, nursing research, and nursing services, as well as in the diabetes associations and 
educational centers in order to improve the quality of nursing care and ultimately to promote health and quality of life in patients with diabetes.

\section{List Of Abbreviations}

Motivational interviewing (MI), Diabetes Management Self-efficacy Scale (DMSES), Self-Monitoring of Blood Glucose (SMBG).

\section{Declarations}

\section{Ethics approval and consent to participate}

This study is approved by the ethics committee of Urmia University of Medical Sciences (Approval code: IR.UMSU.RCC.1395.132). The participants were fully informed about the purpose of the study. Each participant provided written consent prior to participation. They were given explanation regarding their voluntary nature of participation and that they can stop cooperation at any given time. Participants were also assured about the privacy and confidentiality of their information.

\section{Consent for publication}

Not applicable.

\section{Availability of data and material}

The datasets used and analyzed during the current study are available from the corresponding authors on reasonable request.

\section{Competing interests}

The authors declare that they have no competing interests.

\section{Funding}

This study was financially supported by Deputy of Research Council of Urmia Medical Science University.

\section{Author Contributions}

All authors (Masumeh Hemmati Maslakpak, Naser Parizad, Amir Ghahremani and Vahid Alinejad) have actively participated in this study. Design of the study MHM, NP, AG, VA; data collection: NP, AG; analysis and interpretation of data: MHM, NP, AG, VA; manuscript preparation: MHM, NP, AG; manuscript revision, MHM, NP, AG, VA. All authors read and approved the final manuscript before submission.

\section{Acknowledgments}


This article was extracted from a master's thesis in nursing. Hereby, we extend our gratitude to the authorities of the Urmia University of Medical Sciences, the staff of Bukan Diabetes Association, and all the patients who participated and helped us in this research project. We also wish to thank Rosemary Carter for her review of the manuscript and writing assistance.

\section{References}

1. Yarahmadi SH, Etemad K, Hazaveh AM, Azhang N. Urbanization and non-communicable risk factors in the capital city of 6 big provinces of Iran. Iranian journal of public health. 2013;42(Supple1):113118. PMCID: PMC3712588

2. Inzucchi SE, Bergenstal RM, Buse JB, Diamant M, Ferrannini E, Nauck M, Peters AL, Tsapas A, Wender R, Matthews DR. Management of hyperglycemia in type 2 diabetes, 2015: a patient-centered approach: update to a position statement of the American Diabetes Association and the European Association for the Study of Diabetes. Diabetes care. 2015 Jan 1;38(1):140-9. Doi: https://doi.org/10.2337/dc12-0413

3. Shaw JE, Sicree RA, Zimmet PZ. Global estimates of the prevalence of diabetes for 2010 and 2030. Diabetes research and clinical practice. 2010 Jan 1;87(1):4-14. Doi: https://doi.org/10.1016/j.diabres.2009.10.007

4. Breton MC, Guenette L, Amiche MA, Kayibanda JF, Gregoire JP, Moisan J. Burden of diabetes on the ability to work: a systematic review. Diabetes care. 2013 Mar 1;36(3):740-9. Doi: https://doi.org/10.2337/dc12-0354

5. Hisashige A. The effectiveness and efficiency of disease management programs for patients with chronic diseases. Global journal of health science. 2013 Mar;5(2):27-48. Doi: 5539/gjhs.v5n2p27

6. Pimouguet C, Le Goff M, Thiébaut R, Dartigues JF, Helmer C. Effectiveness of disease-management programs for improving diabetes care: a meta-analysis. Canadian Medical Association Journal. 2011;183(2):E115-E27. Doi: 1503/cmaj.091786

7. Kostev K, Rockel T, Jacob L. Impact of disease management programs on HbA1c values in type 2 diabetes patients in Germany. Journal of diabetes science and technology. 2017 Jan;11(1):117-22. Doi: $1177 / 1932296816651633$

8. Graffigna G, Barello S, Libreri C, Bosio CA. How to engage type-2 diabetic patients in their own health management: implications for clinical practice. BMC public health. 2014 Dec;14(1):648. Doi: https://doi.org/10.1186/1471-2458-14-648

9. Miller, William R.; ROLLNICK, Stephen. Motivational interviewing: Helping people change. $3^{\text {rd }}$ Guilford press, 2012.

10. Meybodi FA, Pourshrifi H, Dastbaravarde A, Rostami R, Saeedi Z. The effectiveness of motivational interview on weight reduction and self-efficacy in Iranian overweight and obese women. ProcediaSocial and Behavioral Sciences. 2011 Jan 1;30:1395-8.Doi: https://doi.org/10.1016/j.sbspro.2011.10.271 
11. Powell PW, Hilliard ME, Anderson BJ. Motivational interviewing to promote adherence behaviors in pediatric type 1 diabetes. Current diabetes reports. 2014 Oct 1;14(10):531. Doi: 1007/s11892-0140531-z

12. Ghasemipour Y, Ehsan HB, Abbaspour S, Poursharifi H. The Effectiveness of Motivational Interviewing in Treating Overweight and Obesity of Patients With Coronary Heart Disease. Iranian Journal of Psychiatry \& Clinical Psychology. 2013 Jan 1;18(4): 276-283. Available from: https://www.sid.ir/en/journal/ViewPaper.aspx?ID=332320

13. Minkin A, Snider-Meyer J, Olson D, Gresser S, Smith H, Kier FJ. Effectiveness of a motivational interviewing intervention on medication compliance. Home Healthcare Now. 2014 Sep 1;32(8):490-6. Doi: 1097/NHH.0000000000000128

14. Lavoie KL, Moullec G, Lemiere C, Blais L, Labrecque M, Beauchesne MF, Pepin V, Cartier A, Bacon SL. Efficacy of brief motivational interviewing to improve adherence to inhaled corticosteroids among adult asthmatics: results from a randomized controlled pilot feasibility trial. Patient preference and adherence. 2014; 8:1555. Doi: 2147/PPA.S66966

15. Chen SM, Creedy D, Lin HS, Wollin J. Effects of motivational interviewing intervention on selfmanagement, psychological and glycemic outcomes in type 2 diabetes: a randomized controlled trial. International journal of nursing studies. 2012 Jun 1;49(6):637-44. Doi:

1016/j.jjnurstu.2011.11.011

16. Chien WT, Mui JH, Cheung EF, Gray R. Effects of motivational interviewing-based adherence therapy for schizophrenia spectrum disorders: a randomized controlled trial. Trials. 2015 Dec;16(1):270. Doi: https://doi.org/10.1186/s13063-015-0785-z

17. Navidian A, Abedi MR, Baghban I, Fatehizadeh M, Poursharifi H. Effect of motivational interviewing on blood pressure of referents suffering from hypertension. Kowsar Med J. 2010 Jan 1;15(2):115-21. (Persian). Available from: https://www.sid.ir/en/journal/ViewPaper.aspx?id=175156

18. Naderimagham S, Niknami S, Abolhassani F, Hajizadeh E. Development and psychometric properties of perceived self-efficacy scale (SES) for Self-care in middle-aged patients with diabetes mellitus type 2. Payesh 2013;12(6):679-90. Doi: 1186/1471-2458-12-1035

19. Noroozi A, Tahmasebi R. The diabetes management self-efficacy scale: translation and psychometric evaluation of the Iranian version. Nursing Practice Today. 2014;1(1):9-16. Available from: http://npt.tums.ac.ir/index.php/npt/article/view/3

20. Baer RA, editor. Mindfulness-based treatment approaches: Clinician's guide to evidence base and applications. San Diego, CA, US: Elsevier Academic Press; 2015 Jul 14.

21. Asif M. The prevention and control the type-2 diabetes by changing lifestyle and dietary pattern. Journal of education and health promotion. 2014 Feb 21; 3(1). Doi: 4103/2277-9531.127541

22. Simpson HB, Zuckoff A, Page JR, Franklin ME, Foa EB. Adding motivational interviewing to exposure and ritual prevention for obsessive-compulsive disorder: An open pilot trial. Cognitive Behaviour Therapy. 2008 Mar 1;37(1):38-49. Doi: https://doi.org/10.1080/16506070701743252 
23. Walpole B, Dettmer E, Morrongiello BA, McCrindle BW, Hamilton J. Motivational interviewing to enhance self-efficacy and promote weight loss in overweight and obese adolescents: a randomized controlled trial. Journal of pediatric psychology. 2013 May 13;38(9):944-53. Doi: https://doi.org/10.1093/jpepsy/jst023

24. Song D, Xu TZ, Sun QH. Effect of motivational interviewing on self-management in patients with type 2 diabetes mellitus: a meta-analysis. International Journal of Nursing Sciences. 2014 Sep 1;1(3):2917. Doi: https://doi.org/10.1016/j.ijnss.2014.06.002

25. Bóveda-Fontán J, Barragán-Brun N, Campiñez-Navarro M, Pérula-de Torres LÁ, Bosch-Fontcuberta JM, Martín-Álvarez R, Arbonies-Ortiz JC, Novo-Rodríguez JM, Criado-Larumbe M, Fernández-García JA, Martín-Rioboó E. Effectiveness of motivational interviewing in patients with dyslipidemia: a randomized cluster trial. BMC family practice. 2015 Dec;16(1):151. Doi: https://doi.org/10.1186/s12875-015-0370-2

26. Mojahed K, Navidian A. The effect of motivational interviewing on self-efficacy to quit hookah smoking in pregnant women. Hayat. 2018; 24 (1):84-96. Available from: http://hayat.tums.ac.ir/article-1-2246-en.html

27. Ebrahimi Belil F, Alhani F, Ebadi A, Kazemnejad A. Self-efficacy of people with chronic conditions: A qualitative directed content analysis. Journal of clinical medicine. 2018 Nov 3;7(11):411. Doi: 3390/jcm7110411

28. Sheeran P, Maki A, Montanaro E, Avishai-Yitshak A, Bryan A, Klein WM, Miles E, Rothman AJ. The impact of changing attitudes, norms, and self-efficacy on health-related intentions and behavior: a meta-analysis. Health Psychology. 2016 Nov;35(11):1178. Doi: 1037/hea0000387

29. Hawkins SY. Improving glycemic control in older adults using a videophone motivational diabetes self-management intervention. Research and theory for nursing practice. 2010 Jan 1;24(4):217-232. Doi: 1891/1541-6577.24.4.217

30. Welch G, Zagarins SE, Feinberg RG, Garb JL. Motivational interviewing delivered by diabetes educators: does it improve blood glucose control among poorly controlled type 2 diabetes patients? Diabetes research and clinical practice. 2011 Jan 1;91(1):54-60. Doi: https://doi.org/10.1016/j.diabres.2010.09.036

31. Minet LR, Wagner L, Lønvig EM, Hjelmborg J, Henriksen JE. The effect of motivational interviewing on glycaemic control and perceived competence of diabetes self-management in patients with type 1 and type 2 diabetes mellitus after attending a group education programme: a randomised controlled trial. Diabetologia. 2011 Jul 1;54(7):1620-9. Doi: 1007/s00125-011-2120-x

\section{Figures}


Obtain permission from the University Research Vice President and Ethics Committee

\section{1}

Visit the Bukan Diabetes Association and get permission from the relevant authorities

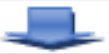

Sampling from Bukan Diabetes Association

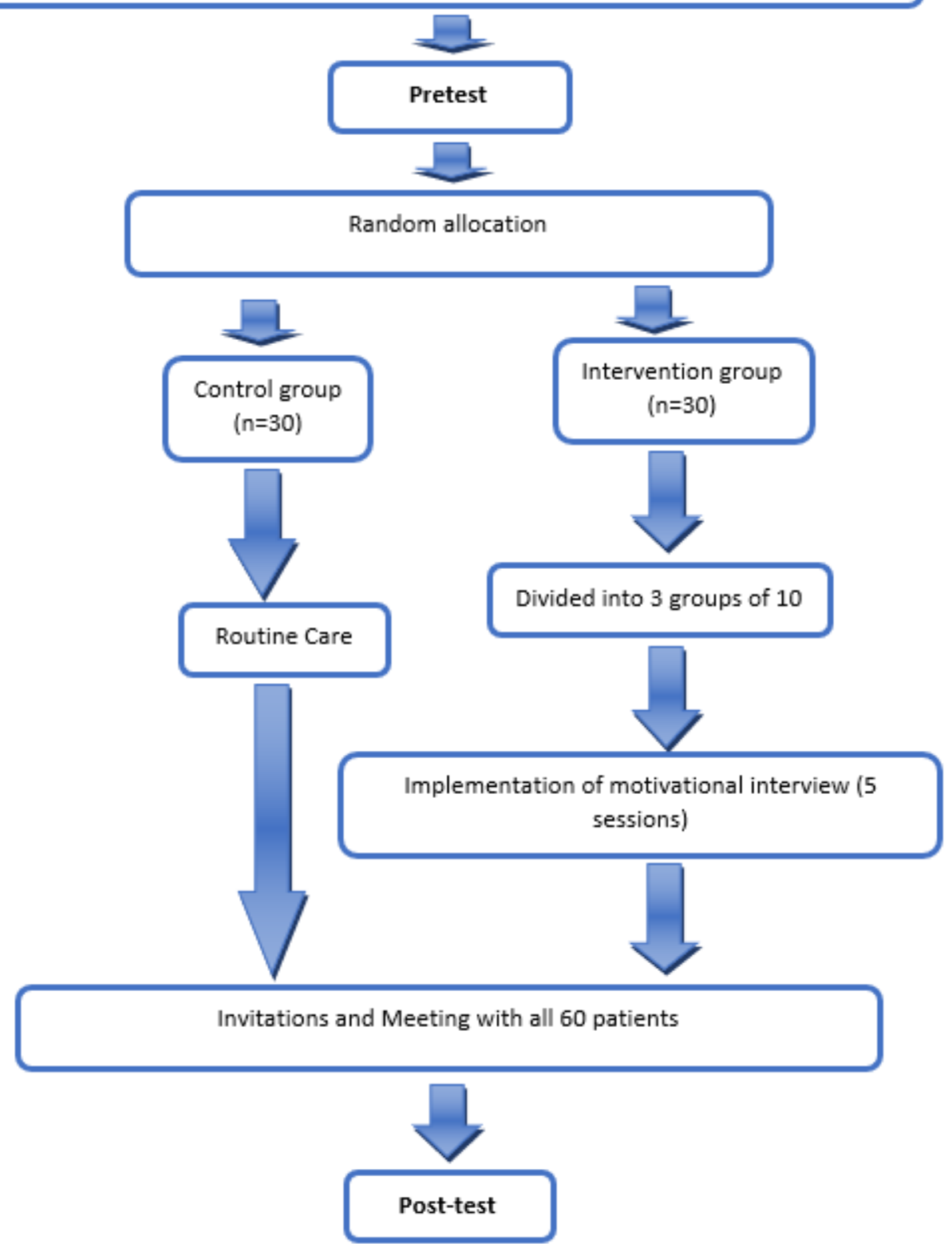

Figure 1

Design methodology flow chart / Analysis was performed on 60 patients who completed the baseline and 4-weeks follow-up assessments (Figure 1). 